\title{
Correction to: Mediation and moderation analyses: exploring the complex pathways between hope and quality of life among patients with schizophrenia
}

Wei-Liang Wang ${ }^{1}$, Yu-Qiu Zhou ${ }^{1 *}$, Nan-Nan Chai ${ }^{2}$, Guo-Hua Li ${ }^{3}$ and Dong-Wei Liu ${ }^{1}$

Correction to: BMC Psychiatry. 20, 22 (2020)

http://orcid.org/0.1186/s12888-020-2436-5

Following the publication of the original article [1], the authors identified errors in Figs. 1 and 2 and Table 2. The correct figures and table are given below.

The original article [1] has been corrected.

The original article can be found online at https://doi.org/10.1186/s12888020-2436-5

*Correspondence: hmuhlxy@163.com

${ }^{1}$ School of Nursing, Harbin Medical University (Daqing), Daqing, Heilongjiang, China

Full list of author information is available at the end of the article

(c) The Author(s). 2021 Open Access This article is licensed under a Creative Commons Attribution 4.0 International License, which permits use, sharing, adaptation, distribution and reproduction in any medium or format, as long as you give appropriate credit to the original author(s) and the source, provide a link to the Creative Commons licence, and indicate if changes were made. The images or other third party material in this article are included in the article's Creative Commons licence, unless indicated otherwise in a credit line to the material. If material is not included in the article's Creative Commons licence and your intended use is not permitted by statutory regulation or exceeds the permitted use, you will need to obtain permission directly from the copyright holder. To view a copy of this licence, visit http://creativecommons.org/licenses/by/4.0/ The Creative Commons Public Domain Dedication waiver (http://creativecommons.org/publicdomain/zero/1.0/) applies to the data made available in this article, unless otherwise stated in a credit line to the data. 
(A)

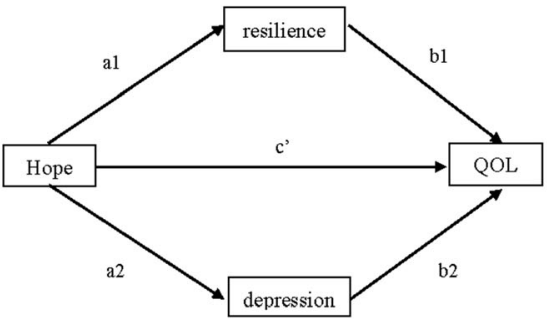

Path c: $B=-0.48^{* * *}$

Path $c^{\prime}: B=-0.271^{* * *}$

Path al: $B=0.457^{* * *}$

Path b1: $B=-0.155^{* *}$

Path a2: $B=-0.287^{* * *}$

Path b2: $B=0.495^{* * *}$
(B)

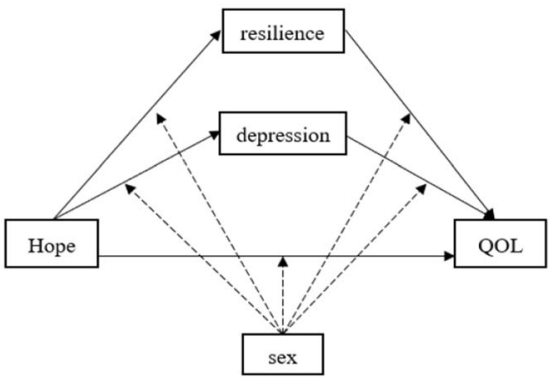

$* \mathrm{p}<0.05 ; * \mathrm{p}<0.01 ; * * * \mathrm{p}<0.001$ QOL: quality of life; H: Hypothesis

Fig. 1 (Panel A: $\mathrm{H} 1$ and $\mathrm{H} 2$ ) Conceptual framework of the Potential Mediating Effect of resilience and depression on the Relationship between hope and QOL. (Panel B: H3) Model of the potential moderating effects on the paths. ${ }^{*} p<0.05 ;{ }^{* *} p<0.01 ;{ }^{* * *} p<0.001$ QOL: quality of life; $\mathrm{H}$ : hypothesis

(A)

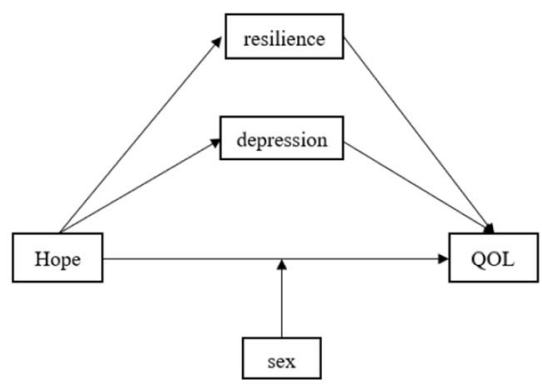

(B)

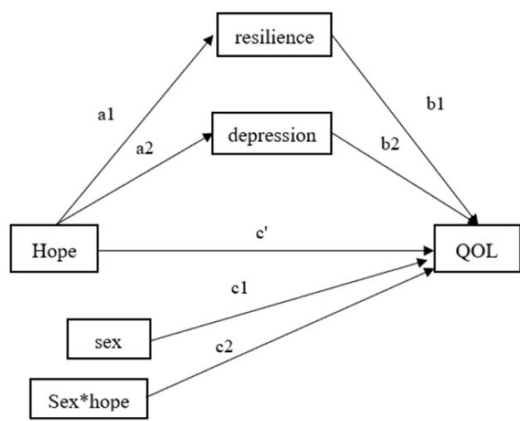

Path a1: $B=0.457^{* * *}$

Path b1: $B=-0.101^{*}$

Path a2: $B=-0.287^{* * *}$

Path $\mathrm{b} 2: B=0.422^{* * *}$

Path $\mathrm{c} 1: B=0.411^{* * *}$

Path $\mathrm{c} 2: B=-0.436^{*}$

Path c': $B=0.033$ (Male)

Path c': $B=-0.403^{* * * *}$ (Female)

$*_{p}<0.05 ; * * p<0.01 ; * * p<0.001$ QOL: quality of life.

Fig. 2 The conceptual (panel A) and statistical (panel B) forms of the conditional process model (moderated mediation). ${ }^{*} p<0.05 ;{ }^{* *} p<0.01 ;{ }^{* * *} p<$ $0.001 \mathrm{QOL}$ : quality of life. In this model, the indirect effect of hope on QOL through depression and resilience and the direct effect of hope on $\mathrm{QOL}$ are supposed to be moderated by sex 
Table 2 Analysis of Simple Effects

\begin{tabular}{|c|c|c|c|c|c|c|c|}
\hline \multirow{2}{*}{$\begin{array}{l}\text { Moderator } \\
\text { variable }\end{array}$} & \multicolumn{7}{|l|}{ Effect } \\
\hline & $\overline{\mathrm{a} 1}$ & b1 & a2 & b2 & $\mathbf{c}^{\prime}$ & a1b1 & $a 2 b 2$ \\
\hline \multicolumn{8}{|l|}{ Gender } \\
\hline Male & $0.435^{* * *}$ & $-0.138^{*}$ & $-0.25^{* *}$ & $0.564^{* * *}$ & $-0.25^{* *}$ & -0.06 & $-0.141^{* *}$ \\
\hline Female & $0.562^{* * *}$ & -0.075 & $-0.405^{* *}$ & $0.335^{* * *}$ & $-0.451^{* * *}$ & -0.042 & $-0.144^{* *}$ \\
\hline Difference & 0.973 & 0.078 & 0.526 & 0.025 & $4.548^{*}$ & 0.005 & 0.253 \\
\hline
\end{tabular}

${ }^{*} p<0.05 ;{ }^{* *} p<0.01 ;{ }^{* * *} p<0.001$

Differences in simple effects were computed by subtracting the effects for women from the effects for men

Tests of differences for the indirect effect were based on bias-corrected confidence intervals derived from bootstrap estimates

Author details

${ }^{1}$ School of Nursing, Harbin Medical University (Daqing), Daqing, Heilongjiang,

China. ${ }^{2}$ School of Nursing, Chifeng University Chifeng, Harbin, The

Autonomous Region, China. ${ }^{3}$ Chifeng Anding Hospital Chifeng, Chifeng, The

Autonomous Region, China.

Published online: 12 November 2021

\section{Reference}

1. Wang $W L$, et al. Mediation and moderation analyses: exploring the complex pathways between hope and quality of life among patients with schizophrenia. BMC Psychiatry. 2020;20(1):22 